\title{
Analisis Perubahan Nilai Tanah Akibat Erupsi Gunung Kelud Tahun 2014 di Kecamatan Ngancar Kabupaten Kediri
}

\author{
Mohammad Ibnu Aqil dan Yanto Budisusanto \\ Departemen Teknik Geomatika, Fakultas Teknik Sipil dan Perencanaan, Institut Teknologi Sepuluh \\ Nopember (ITS) \\ e-mail: yanto_b@geodesy.its.ac.id
}

\begin{abstract}
Abstrak-Erupsi Gunung Kelud tahun 2014 ini mengakibatkan kerusakan pemukiman, kerusakan fasilitas umum, serta kerusakan ladang-ladang sekitarnya. Kecamatan Ngancar merupaka salah satu daerah yang terkena dampak secara langsung karena terletak di lereng Gunung Kelud. Terjadinya perubahan kondisi fisik suatu wilayah dapat memicu perubahan nilai tanah di area tersebut. Penelitian ini bertujuan untuk mengehitung perubahan nilai tanah. Penelitian ini dilakukan dengan menumpang tindihkan peta zona nilai tanah Kecamatan Ngancar Kabupaten Kediri tahun 2013, 2014, dan 2015 menggunakan perangkat lunak pengolah data spasial untuk menghitung besar nilai tanah yang terjadi di lokasi penelitian. Data perubahan nilai tanah tersebut kemudian dilakukan uji korelasi dengan variabel bebas yaitu jarak zona terhadap pusat letusan, jarak zona dari CBD, dan jarak zona dari jalan kolektor. Tujuannya ialah mengetahui seberapa besar pengaruh erupsi Gunung Kelud terhadap perubahan nilai tanah. Berdasarkan penelitian yang telah dilakukan, terjadi perubahan nilai tanah di Kecamatan Ngancar Kabupaten Kediri. Menurut hasil uji korelasi, erupsi Gunung Kelud 2014 tidak memiliki pengaruh yang besar terhadap perubahan nilai tanah. Sehingga aktifitas gunung api bukan merupakan penyebab utama perubahan nilai tanah di Kecamatan Ngancar.
\end{abstract}

Kata Kunci-Nilai Tanah, Kecamatan Ngancar, Gunung Kelud

\section{PENDAHULUAN}

$\mathrm{N}$ ILAI tanah (Land Value) didefinisikam sebagai pengukuran nilai tanah yang didasarkan atas kemampuan tanah secara ekonomis dalam hubungannya dengan strategi ekonimi dan produktivitasnya. Sedangkan nilai tanah itu sendiri merupakan perwujudan dari kemampuan tanah dalam hubungannya dengan penggunaan dan pemanfaatan tanah [1]. Perubahan kondisi fisik dan lingkungan suatu wilayah bisa menjadi pemicu terjadinya perubahan seperti kerusakan lingkungan dan fasilitas umum. Salah satu penyenbab kondisi lingkungan berubah ialah bencana alam gunu meletus seperti yang terjadi pada Gunung Kelud tahun 2014

Gunung Kelud merupakan salah satu gunung aktif yang ada di Pulau Jawa. Gunung ini telah mengalami 32 kali erupsi sejak tahun 1300 hingga tahun 2014 dan menyebabkan kerusakan 45.162 hektar lahan pertanian dan 15381 korban jiwa $^{[2]}$. Erupsi 2014 menyebabkan kerusakan. baik dari segi lingkungan dan fisik maupun di bidang sosial ekonomi. Sarana dan prasarana mengalami kerusakan akibat tumpukan material hasil erupsi Gunung Kelud terlebih lagi pada daerah yang lokasinya bera di lereng gunung salah satunya ialah Kecamatan Ngancar Kabupaten Kediri.

Kecamatan Ngancar merupakan akses utama menuju ke area wisata Gunung Kelud Kabupaten Kediri dan merupakan daerah yang terkena dampak paling parah dari Erupsi Gunung Kelud 2014 [2]. Masyarakat yang hidup di kecamtan ini sebagian sebagai petani [3]. Akan tetapi lahan di lereng Gunung Kelud mengalami kerusakan pasca terjadinya erupsi sehingga banyak petani yang mengalami gagal panen serta mendapatkan kerugian. Rusaknya lingkungan sekitar, sarana prasarana, dan beberapa bangunan mengalami kerusakan hingga perubahan sosial yang dialami oleh kecamatan tersebut dapat mempengaruhi nilai jual bidang tanah di kawasan itu seperti yang terjadi pada Kecamatan Banntul dan Kecamatan Jetis Kabupeten Bantul dimana nilai tanahnya mengalami penurunan akibat gempa bumi di Yogyakarta pada tahun 2006 [4].

Dengan setatus Gunung Kelud yang masih aktif, kondisi seperti ini memiliki kemungkinan akan terulang lagi di hari mendatang. Sehingga, diperlukan analisis perubahan nilai tanah setelah terjadinya erupsi Gunung Kelud dengan membandingkan nilai tanah sebelum dan setelah terjadinya letusan. Diharapkan masyarakat dapat melakukan antisipasi jika terjadi erupsi di kemudian hari.

\section{METODOLOGI}

\section{A. Lokasi Penelitian}

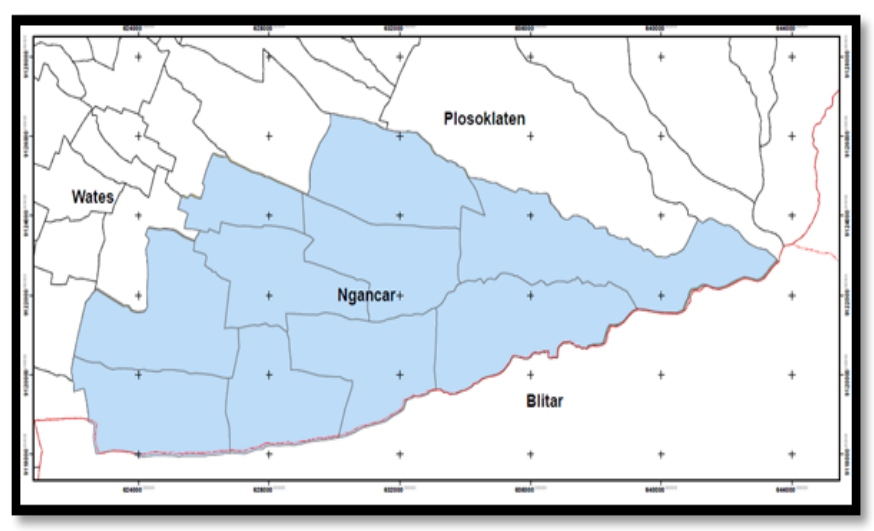

Gambar 1 Lokasi Penelitian

Lokasi dari penelitian yaitu Kecamatan Ngancar, Kabupaten Kediri, Jawa Timur, Indonesia. Luas wilayah 94,05 $\mathrm{km}^{2}$. Lokasi geografisnya terletak pada $112^{\circ} 6^{\prime} 45^{\prime}$ " sampai dengan $112^{\circ} 18^{\prime} 20^{\prime \prime}$ Bujur Timur dan 7053'20" sampai dengan 7058'45" Lintang Selatan. Batas wilayah Kecamatan Ngancar ialah [1]:
$\checkmark$ Utara
: Kec. Plosoklaten
$\checkmark$ Selatan
: Kab. Blitar
$\checkmark$ Barat
: Kec. Wates
$\checkmark$ Timur 


\section{B. Alat dan Bahan}

1 Alat

Penelitian ini memerlukan beberapa peralatan pendukung yang terdiri dari:

a. Perangkat Keras

i. Seperangkat computer.

ii.GPS Handheld

b. Perangkat Lunak

i.Perangkat lunak pengolah kata dan spreadsheet

ii.Perangkat lunak pengolah data spasial

2 Bahan

iii.Perangkat lunak pengolah data statistik

Bahan (data) yang digunakan dalam penelitian ini adalah sebagai berikut:

a. Peta Administrasi Kecamatan Ngancar, Kabupaten Kediri skala 1:25.000yang didapatkan dari website Ina-Geoposrta.

b. Peta jaringan jalan Kabupaten Kediri skala 1:25.000yang didapatkan dari website Ina-Geoportal.

c. Peta ZNT Kecamatan Ngancar Kabupaten Kediri tahun 2013, 2014, dan 2015 yang didapatkan dari Kantor Pertanahan Kabupaten Kediri.

d. Titik lokasi letusan Gunung Kelud yang didapatkan dari peta rawan bencana BNPB.

e. Lokasi titik CBD yang didapatkan dari pengukuran langsung.

\section{Langkah Pengerjaan}

Adapun langkah pengerjaan penelitian ini ialah sebagai berikut:

1. Studi literatur dilakukan untuk mencari informasi berkaitan dengan masalah yang sedang diteliti baik secara teori maupun praktik. Informasi tentang perubahan nilai tanah dan pengaruh erupsi Gunung Kelud terhadap wilayah sekitar khususnya di Kecamatan Ngancar, Kabupaten Kediri.

2. Pengumpulan data dilakukan secara primer dan sekunder. Data yang dihimpun adalah data spasial dan non spasial. Data spasial meliputi, koordinat titik-titik CBD, koordinat titik yang diperoleh dari survei lapangan, pusat letusan yang didapat dari Peta Rawan Bencana Gunung Kelud 2014 oleh BNPB. data Peta Zona Nilai Tanah (ZNT) 2013, 2014, dan 2015 yang diperoleh dari BPN Kabupaten Kediri, data jaringan jalan Kabupaten Kediri yang didapat dari website InaGeoportal, Peta Batas Administrasi Kabupaten Kediri yang diperoleh dari website Ina-Geoportal. Data non spasial adalah sebuah kuisioner sebagai pendukung penelitian yang dikumpulkan langsung di lapangan.

3. Melakukan overlay Peta ZNT 2013 dan ZNT 2014 untuk mengetahui perbedaan nilai tanah antara tahun 2013 sampai 2014 dari tiapa-tiap zona. Melakukan overlay Peta ZNT tahun 2014 dan 2015 untuk mengetahui perubahan nilai tanah yang terjadi antara tahun 2014 sampai 2015. Tujuannya ialah membandingkan kedua data tersebut untuk mengetahui seberapa besar perubahan nilai tanah di sekitar Lereng Gunung Kelud setelah terjadinya erupsi.

4. Melakukan plotting data Administrasi Kabupaten Kediri, Jaringan Jalan Kabupaten Kediri. Titik CBD dan Titik Pusat Letusan Gunung Kelud kedalam sebuah software pengolahan data spasial untuk mempermudah dalam proses selanjutnya.
5. Memasukkan data perubahan nilai tanah hasil dari overlay ZNT 2013-2014 dan ZNT 2014-2015 ke dalam software pengolahan bersama dengan data spasial lain yang telah diplotting sebelumnya. Proses ini digunakan untuk menetukan besarnya nilai variable yang dipakai. Variable tersebut ialah jarak zona meneju ke pusat letusan, jarak zona ke CBD, dan jarak zona ke jalan kolektor. Jarak yeng digunakan ialah jarak centeroid zona nilai tanah dengan variabel yang sudah disebutkan.

6. Melakukan korelasi antara perubahan nilai tanah yang terjadi dengan variable-variabel perubahan nilai tanah yang telah ditentukan untuk mengetahui seberapa besar hubungan antar perubahan nilai tanah yang terjadi dengan veriabel-variabel tersebut.

7. Membuat peta perubahan nilai tanah 2013-2014 dan 2014-2015 untuk memberikan informasi seberapa besar perubahan nilai tanah yang terjadi.

\section{HASIL DAN ANALISA}

\section{A. Hasil Perubahan Nilai Tanah}

Data yang digunakan dalam penelitian kali ini adalah ZNT milik Badan Pertanahan Nasional tahun 2013, 2014, dan 2015. Perubahan nilai tanah di Kecamatan Ngancar Kabupaten Kediri didapkan dengan cara melakukan overlay peta yang telah didapat. Adapun perubahan nilai tanah yang terjadi bisa dilihat dalam table 1 dan 2 sebagai berikut:

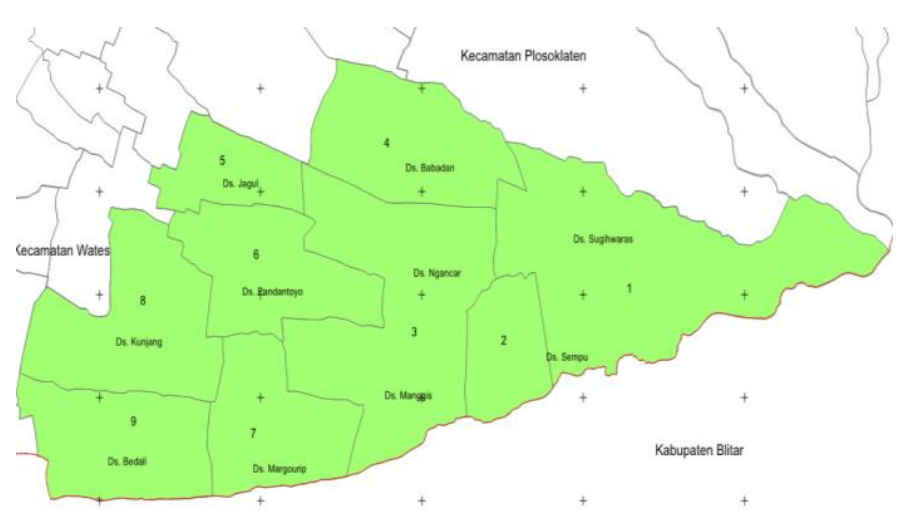

Gambar 2. Peta Blok

Setelah terjadi erupsi Gunung Keluddari tahun 2014, kondisi zona nilai tanah di Kecamatan Ngancar Kabupaten Kediri tidak mengalami perubahan jumlah zona. Duntuk perubahan nilai tanahnya biasa dilihat pada table 1 dan 2. Dari data tabel yang telah disajikan dapat dilihat bahawa setelah terjadinya bencana alam erupsi Gunung Kelud nilai tanah disana mengalami perubahan. Pada tahun 2013-2014 perubahan nilai hanya terjadi pada 3 zona dengan kenaikan maksimal 5\% sedangkan pada tahun 2014-2015 kenaikan terjadi di semua zona dengan kenaikan lebi dari $100 \%$.

Tabel 1.

Perubahan Nilai Tanah 2013-2014

\begin{tabular}{cccc}
\hline \hline Blok Zona & $\begin{array}{c}\text { Nilai Tanah } \\
2013\end{array}$ & $\begin{array}{c}\text { Nilai Tanah } \\
2014\end{array}$ & Perubahan(\%) \\
\hline 1 & 20000 & 21000 & 5 \\
2 & 63000 & 63000 & 0 \\
3 & 67000 & 67000 & 0 \\
4 & 16000 & 16000 & 0 \\
5 & 27000 & 27000 & 0 \\
6 & 51000 & 52000 & 2 \\
7 & 16000 & 16000 & 0 \\
8 & 20000 & 21000 & 5
\end{tabular}


13000

13000

0

Tabel 2.

Perubahan Nilai Tanah 2014-2015

\begin{tabular}{cccc}
\hline \hline Blok Zona & $\begin{array}{c}\text { Nilai Tanah } \\
2014\end{array}$ & $\begin{array}{c}\text { Nilai Tanah } \\
2015\end{array}$ & Perubahan(\%) \\
\hline 1 & 21000 & 43000 & 105 \\
2 & 63000 & 131000 & 108 \\
3 & 67000 & 140000 & 109 \\
4 & 16000 & 34000 & 113 \\
5 & 27000 & 56000 & 107 \\
6 & 52000 & 151000 & 190 \\
7 & 16000 & 34000 & 113 \\
8 & 21000 & 43000 & 105 \\
9 & 13000 & 27000 & 108 \\
\hline \hline
\end{tabular}

\section{B. Analisa Perubahan Nilai Tanah.}

\section{1) Pengukuran Jarak Variabel}

Variabel penentu nilai tanah yang digunakan dalam penelitian ini ada 3 yaitu jarak zona ke pusat letusan, jarak zona ke CBD atau lokasi pusat bisnis ( dalam penelitian kali titik CBD yang digunakan ialah pasar), jarak zona ke jalan kolektor. Variabel yang dipilih disesuaikan dengan keadaan yang ada dilapangan, jarak dari pusat letusan sebagai variable penentu utama untuk mengetahui pengaruh bencana alam terhadap perubahan nilai tanah. 2 variabel lain digunakan sebagai pembanding dimana jarak dari CBD dipilih sebgai faktor lokasi dan jarak dari jalan kolektor sebagai faktor lingkungan.

Pengukuran dilakukan menggunakan perangkat lunak pengolah data spasial dengan terlebih dahulu mencari titk pusat atau centeroid dari masing-masing zona. Dari titik centeroid tersebut kemudian diukur jaraknya ke variabel yang telah digunakan menggunakan salah satu tools dalam perangkat lunak. Hasil pengukuran dapat dilihat dalam tabel 3.

Tabel 3.

Hasil Pengukuran Variabel

\begin{tabular}{ccccc}
\hline \hline Blok Zona & $\begin{array}{c}\text { Pusat } \\
\text { Letusan } \\
(\mathrm{KM})\end{array}$ & CBD $(\mathrm{KM})$ & $\begin{array}{c}\text { Jalan } \\
\text { Kolektor } \\
(\mathrm{KM})\end{array}$ & $\begin{array}{c}\text { Perubaha } \\
\text { n Nilai } \\
(\%)\end{array}$ \\
\hline 1 & 7.17 & 13.58 & 23.8 & 105 \\
2 & 10.86 & 10.4 & 20.23 & 108 \\
3 & 13.56 & 7.52 & 17.61 & 109 \\
4 & 13.35 & 7.65 & 17.66 & 113 \\
5 & 17.71 & 13.4 & 13.24 & 107 \\
6 & 16.56 & 4.37 & 14.5 & 190 \\
7 & 16.79 & 6.06 & 14.3 & 113 \\
8 & 20.01 & 2.49 & 11.25 & 105 \\
9 & 20.62 & 4.72 & 10.5 & 108 \\
\hline \hline
\end{tabular}

\section{2) Analisa Korelasi}

Sebelum melakukan analisa korelasi menggunakan software pengolah data statistik, terlebih dahulu dilakukan pengukuran jarak masing-masing variabel penentu nilai tanah terhadap lokasi survei. Perhitungan analisa korelasi menggunakan data perubahan nilai tanah yang diperoleh dari hasil overlay peta ZNT milik BPN dan perhitungan jarak masing-masing variabel yang telah dilakukan dengan menggunakan perangkat lunak pengolah data spasial. Rumus perhitungan korelasi dapat dilihat di bawah ini:

$$
r=\frac{n\left(\sum x y\right)-\left(\sum x\right) \cdot\left(\sum y\right)}{\sqrt{n\left(\sum x^{2}\right)-\left(\sum x\right)^{2} n\left(\sum y^{2}\right)-\left(\sum y\right)^{2}}}
$$

Keterangan: $\mathrm{r}$ = hubungan variabel $\mathrm{X}$ dengan Variabel $\mathrm{Y}$

$X=$ Nilai variabel $X$

$\mathrm{Y}=$ Nilai variabel $\mathrm{Y}$

Hasil pengolahan dari software pengolah statistik akan disajikan dalam table sebagai berikut:

Tabel 4.

Uji Korelasi Perubahan Nilai Tanah 2013-2014

\begin{tabular}{cc} 
Variabel & $r$ \\
\hline Pusat Letusan & -0.174 \\
CBD & -0.064 \\
Jalan & 0.179 \\
\hline \hline
\end{tabular}

Tabel 5.

Uji korelasi Perubahan Nilai Tanah 2014-2015

\begin{tabular}{cc}
\hline \hline Variabel & $\mathrm{r}$ \\
\hline Pusat Letusan & 0.123 \\
CBD & -0.341 \\
Jalan & -0.127 \\
\hline \hline
\end{tabular}

Menurut korelasi yang telah dilakukan pada data perubahan nilai tanah tahun 2013-2014 dan 2014-2015 menunjukkan bahwa variabel pusat letusan memiliki dampak yang rendah terhadap perubahan nilai tanah di Kecamatan Ngancar kabupaten Kediri dibandingkan dengan variabel lainnya. Meskipun hasil perhitungan dari ketiga faktor dikatankan rendah, dari table 4 terlihat bahwa pada tahun 2013-2014 pengaruh tertinggi dipengaruhi oleh variabel jarak dari jalan kolektor dengan nilai korelasi sebesar 0,179 dan pada tahun 2014-2015 jarak dari CBD merupakan variabel yang memiliki pengaruh tinggi dibandingkan yang lain sebesar $-0,341$. Sehingga dapat disimpulakan bahwa bencana alam erupsi Gunung Kelud tidak memiliki Pengaruh yang signifikan terhadap perubahan nilai tanah. Apabila terjadi erupsi lagi di kemudian hari, tidak akan memberi dampak yang besar terhadap perubahan nilai tanah di area lereng Gunung Kelud.

\section{Peta Perubahan Nilai Tanah}

Peta perubahan ini terdiri dari 2 peta, peta pertama menjelaskan tentang presentase perubahan nilai tanah yang terjadi pada tahun 2013-2014 dan peta kedua menjelaskan tentang presentase perubahan nilai tanah yang terjadi pada tahun 2014-2015. Dari peta ini dapat diketahui lokasi mana yang mengalami perubahan tertinggi dan terendah serta menapilkan seberapa besar nilai perubahannya di masingmasing zona Kecamatan Ngancar Kabupaten Kediri.

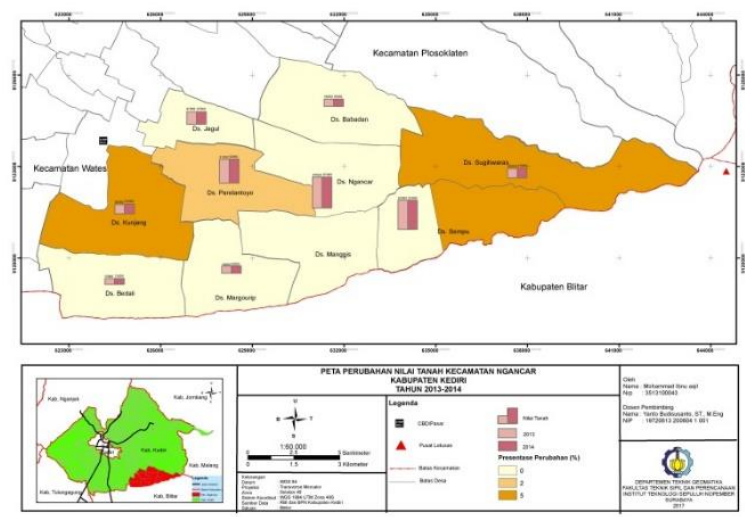

Gambar 3. Peta perubahan nilai tanah di Kecamatan Ngancar KabupatenKediri terjadi pada tahun 2013-2014. 

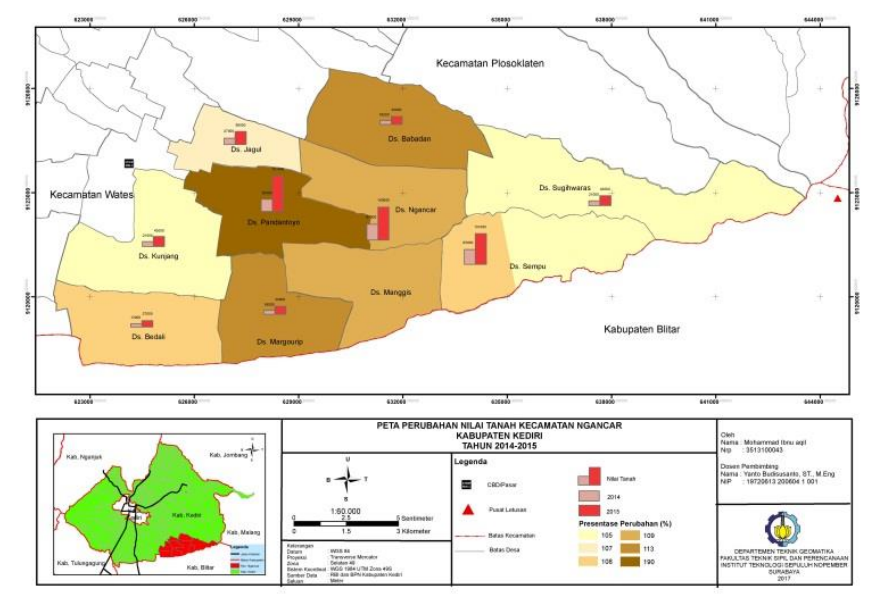

Gambar 4. Peta perubahan nilai tanah di Kecamatan Ngancar Kabupaten Kediri terjadi pada tahun 2014-2015

\section{KESIMPULAN DAN SARAN}

\section{A. Kesimpulan}

Adapun kesimpulan yang dapat diambil dari penelitian kali ini adalah sebagai berikut:

1. Terjadi perubahan nilai tanah di Kecamatan Ngancar Kabupaten Kediri setelah terjadinya erupsi Gunung Kelud. Nilai tanahnya tetap meningkat seiring dengan perubahan tahun .

2. Dari hasi uji korelasi varibel jarak dari pusat letusan, jarak dari pusat CBD, dan jarak dari jalan kolektor tidak terlalu berpengaruh terhadap perubahan nilai tanah. Dimana Faktor jarak dari pusat letusan yang merupakan variabel yang mewakili bencana erupsi hanya mendapatkan $\mathrm{r}=$ 174 pada 2014 dan $r=0.123$. nilai tersebut masih lebih rendah dari pada r-variabel jarak dari jalan pada 2013 2014 dan r-variabel jarak CBD pada 2014-2015. Sehingga erupsi gunung api tidak mempunyai dampak besar pada perubahan nilai tanah.

\section{B. Saran}

Saran yang dapat diberikan dari pelaksanaan penelitian ini yaitu:

1. Mencari variabel penentu nilai tanah yang sangat berpengaruh di daerah penelitian agar tingkat pengaruh variabel semakin tinggi. Jika tingkat pengaruh variabel semakin tinggi, maka penyebab utama perubahan nilai tanah bisa diketahui.

2. Memperluas studi kasus penelitian sehingga bisa mendapat jumlah sempel data yang lebih banyak dan bisa lebih akurat.

\section{UCAPAN TERIMA KASIH}

Penulis M.I.A mengucapkan terima kasih kepada Badan Pertanahan Nasional Kabupaten Kediri yang telah menyediakan data zona nilai tanah Kabupaten Kediri, Pemerintah Kabupaten Kediri yang telah mengizinkan penulis untuk melakukan pengambilan data penelitian ini.

\section{DAFTAR PUSTAKA}

D. Sujarto, Perencanaan Kota Baru. Bandung: ITB, 1986.

D. Wardhani, Dampak Erupsi Gunungapi Kelud Tahun 2014 pada Kondisi Sosial dan Ekonomi Masyarakat. 2014.

[3] B. K. Kediri, Kecamatan Ngancar Dalam Angka. Kediri: BPS Kabupaten Kediri. 2016.

[4] W. Yulaikhah., Nuryanti, U., "Analisis Perubahan Nilai Tanah Akibat Gempa Bumi 27 Mei 2006 Di Kecamatan Bantul Dan Kecamatan Jetis Kabupaten Bantul," Media Teknik, pp. 269-275, 2008. 